\title{
An audit on medical students' exposures to bio-hazards during cadaveric dissections
}

Mathangasinghe $\mathrm{Y}^{1}$, Maddumaarachchi $\mathrm{HSTM}^{1}$, Samaranayake UMJE${ }^{1}$, Perera MHS ${ }^{1}$, Anthony $\mathrm{DJ}^{1}$, Malalasekera $\mathrm{AP}^{1}$

${ }^{I}$ Department of Anatomy, Faculty of Medicine, University of Colombo, Colombo, Sri Lanka

\section{Introduction}

Medical students are exposed to a wide range of potentially hazardous materials during cadaveric dissections. Therefore, we intended to study the prevalence of occupational exposure to biohazards and the safety measures taken by students.

\section{Methods}

An audit was conducted among two batches of medical students of the Faculty of Medicine, University of Colombo, soon after completion of the Anatomy curriculum. The study conformed to the guidelines of the declaration of Helsinki. Exposures, practices, prevention methods, health conditions of the students, their suggestions to improve safety measures and self-reported frequency of engaging in dissections in each session (as measured in a ten-point Likert scale) were assessed using a validated selfadministered questionnaire.

\section{Results}

Of 196 respondents, $50 \%(n=98)$ were males. Mean age was $21.8 \pm 1.1$ years. D u r i n t h e i r first-y e a r dissections, $15.8 \%(n=31)$ had cut injuries, $86.7 \%(\mathrm{n}=170)$ had skin contact with cadaver fluids while $5.6 \%(\mathrm{n}=11)$ had eye splashes. Of those with skin contact, $43.5 \%(n=74)$ washed immediately. Of those who had eye splashes, only $18.2 \%(n=2)$ washed immediately for 20 minutes as recommended by the WHO. Nine students reported new nail infections, 7 developed allergies to cadaver fluids and 15 developed skin rashes during the period of dissections. Mean score of the self-reported frequency of engaging in dissection was $7 / 10(\mathrm{SD}=3 / 10)$. Pearson's correlations showed that the self-reported frequency of engaging in dissections positively correlated with the frequency of skin contact with cadaveric fluids $(\mathrm{r}=.161, \mathrm{p}=0.035)$, but not with the frequency of cut injuries( $p>.05)$ or eye splashes( $p>.05)$. Students suggested the following safety measures: $63.3 \%(\mathrm{n}=72)-1 \mathrm{ab}$ coats, $55.6 \%(\mathrm{n}=109)-$ masks, $16.8 \%(n=33)$-goggles, $43.9 \%(n=86)$-a lecture on lab safety, $44.4 \%(n=87)-a$ workshop and $40.3 \%(n=79)$-a formal safety protocol.

\section{Discussion and Conclusions}

Given the numerous exposures to biohazards in the Anatomy laboratory we found that there is a gap between the current practice and the internationally recommended safety measures. Therefore, findings of this study should be taken into consideration in developing policies and improving awareness among students. 